Pesquisa Florestal Brasileira $\begin{aligned} & \text { Peira } \\ & \text { Brazilian Journal of Forestry Research } \\ & \text { http://pfb.cnpf.embrapa.br/pfb/ }\end{aligned}$

\title{
Produtividade de minicepas de três espécies florestais em diferentes tamanhos de tubetes
}

\author{
TeresaAparecida Soares de Freitas ${ }^{1 *(D)}$, Sandra Selma Marques de Souza1(iD), Lucas Barbosa dos Santos ${ }^{1}$ (iD), Andrea Vita Reis Mendonça ${ }^{1}$ (iD \\ ${ }^{1}$ Universidade Federal do Recôncavo da Bahia, Rua Rui Barbosa, 710, CEP 44380-000, Cruz das Almas, BA, Brasil
}

"Autor correspondente:

tas_freitas@hotmail.com

Termos para indexação:

Miniestacas

Propagação vegetativa

Espécies nativas

Index terms:

Minicuttings

Vegetative propagation

Native species

\section{Histórico do artigo:}

Received in 29/11/2017

Accepted in 04/09/2018

Published in 12/12/2018

doi: 10.4336/2018.pfb.38e201701548

\begin{abstract}
Resumo - Avaliou-se a produtividade e sobrevivência de minicepas de Poincianella pyramidalis, Senegalia bahiensis e Enterolobium contortisiliquum em diferentes tamanhos de tubetes. Foram implantados em minijardim multiclonal, conduzido em delineamento inteiramente casualizado (DIC), contendo três tratamentos (tubetes de $50,180,280 \mathrm{~cm}^{3}$ ), considerando os experimentos de 1 a 3, P. pyramidalis $S$. bahiensis e E. contortisiliquum, respectivamente. As variáveis analisadas foram sobrevivência das minicepas após sucessivas coletas, número de brotações por minicepa a cada 15 dias e número de miniestacas por minicepa após sucessivas coletas. Realizou-se análise de variância e teste de Tukey a 5\% de probabilidade para os dados que apresentaram normalidade. Observou-se alta sobrevivência das minicepas para as três espécies, após sucessivas coletas de miniestacas, indicando assim potencial para uso da técnica de miniestaquia. Foi também observado que o uso de tubetes de volumes reduzidos pode afetar de forma negativa a produtividade de brotações e consequentemente o número de miniestacas por minicepa.
\end{abstract}

\section{Productivity of ministumps of three forest species in different tubes sizes}

\section{Introdução}

A propagação de espécies florestais nativas é realizada predominantemente por sementes, entretanto, a irregularidade de sua produção para muitas espécies dificulta a obtenção das mudas (Dias et al., 2012). Além disso, a propagação via sementes fornece povoamentos heterogêneos, aumentando os custos operacionais de manutenção e colheita (Ferreira et al., 2004).

Para algumas espécies nativas, há pesquisas sobre o uso da técnica de propagação vegetativa, porém é assunto pouco abordado, dado à alta diversidade 
existente no Brasil e, além disso, a maior parte se refere às espécies exóticas (Freitas et al., 2017).

$\mathrm{Na}$ reprodução assexuada existe a preocupação quanto à diversidade genética, que é necessária quando o objetivo é a recomposição e recuperação de áreas degradadas (Dias et al., 2012). Neste sentido, esta diversidade pode ser viabilizada utilizando a técnica de minijardim multiclonal, em que as mudas fornecedoras de miniestacas poderão resultar de sementes de diferentes matrizes, garantindo a diversidade genética almejada (Wendling et al., 2005).

Assim, o minijardim multiclonal é constituído por mudas produzidas via sementes que serão podadas a uma determinada altura para estímulo de emissão de novas brotações, que por sua vez serão coletadas periodicamente para confecção das miniestacas destinadas à produção das mudas.

Estudos têm demonstrado a viabilidade da miniestaquia na produção de mudas de Eucalyptus spp. (Cunha et al., 2005), Erythrina falcata Benth. (Cunha et al., 2008), Grevillea robusta (Souza Junior et al., 2008), Araucaria angustifolia (Wendling et al., 2009), Calophyllum brasilinsis (Silva et al., 2010), Piptocarpha angustifolia (Ferriani et al., 2011), Myracrodruon urundeuva (Diógenes et al., 2013; Justino et al., 2017), Jatropha curca (Pimenta et al., 2014), Toona ciliata (Souza et al., 2014) e Handroanthus heptaphyllus (Oliveira et al., 2015). Todas as pesquisas utilizaram a semente como fonte de propágulo para a produção das minicepas, que foram conduzidas em tubetes ou sacolas plásticas, com exceção de Piptocarpha angustifolia, em que as minicepas foram conduzidas em canaletão.

Poicianella pyramidalis, Senegalia bahiensis e Enterolobium contortisiliquum são espécies nativas do Brasil com grande potencial econômico e ambiental. Porém a carência de informações sobre sua utilização e propagação é muito grande, existindo uma imensa lacuna sobre sua forma de propagação vegetativa. $\mathrm{Na}$ literatura existem poucos trabalhos sobre a propagação vegetativa de quaisquer das três espécies. Os assuntos abordados com Poincianella pyramidalis tratavam de recipiente, substrato, luminosidade (Dantas et al., 2009, 2011; Coelho et al., 2013; Antunes et al., 2014) e sementes (Lima et al., 2014; Mendonça et al., 2014, 2016). Com Senegalia bahiensis (Benth.) Seigler \& Ebinger, foram encontrados estudos na área de florística, fitossociologia (Barbosa et al., 2012; Ferreira et al., 2013; Costa et al., 2015) e sementes (Lima et al.,
2017). E para Enterolobium contortisiliguum podem ser citados os estudos de Abreu et al. (2015) (produção de mudas), Scalon et al. (2006); Araújo \& Paiva Sobrinho (2011); Barretto \& Ferreira (2011); Gonçalves et al. (2013) e Silva et al. (2014) (substratos); e Melo et al. (2008) e Lima et al. (2010) (efeito do sombreamento no crescimento das mudas).

As técnicas de propagação vegetativa constituem uma alternativa para superar as dificuldades encontradas na propagação de espécies nativas (Dias et al., 2012). Os avanços na técnica de estaquia culminaram com a atual propagação clonal, via miniestaquia (Xavier et al., 2013), que de acordo com os autores apresenta vantagens em relação à estaquia tradicional, como maior facilidade no controle de patógenos, nutrição e balanço hídrico; maior produtividade; maior produção de propágulos por área e em menor tempo; melhor resposta ao enraizamento das miniestacas; formação da muda em menor tempo; entre outras.

Além disso, a técnica de minijardim tem potencial para ser empregada em pequenas e médias propriedades, podendo resultar em incremento de renda na agricultura familiar (Ferriani et al., 2011).

Os minijardins são construídos, normalmente, em sistema de canaletão ou em tubetes. Entretanto, Silva et al. (2012) ressaltam que a utilização de tubetes possibilita monitoramento nutricional e fitossanitário individualizado, facilitando o manejo da produção. Assim, na opção de utilização de tubetes para a finalidade de minijardim é preciso definir o volume mais adequado que permita maior produtividade das minicepas, além de sua sobrevivência.

Sendo assim, o objetivo desse trabalho foi avaliar a produtividade e sobrevivência das minicepas de Poincianella pyramidalis, Senegalia bahiensis e Enterolobium contortisiliquum em diferentes volumes de tubetes, em coletas sucessivas.

\section{Material e métodos}

O trabalho foi conduzido no viveiro do Centro de Ciências Agrárias, Ambientais e Biológicas da Universidade Federal do Recôncavo da Bahia, no município de Cruz das Almas, Bahia.

As espécies selecionadas foram Poincianella pyramidalis, Senegalia bahiensis e Enterolobium contortisiliquum. 
Poincianella pyramidalis (Tul.) L. P. Queiroz, endêmica do Brasil, de ocorrência confirmada no Norte (AM) e Nordeste (AL, BA, CE, MA, PB, PE, PI e SE) (Fabaceae, 2018), é conhecida como catingueira e catinga-de-porco, família Fabaceae-Caesalpinoideae (Leite \& Machado, 2009). É utilizada na produção de carvão vegetal, lenha, restauração florestal, forragem para gado e aplicações industriais (Maia, 2004). No trabalho realizado por Melo et al. (2010), foram identificadas atividades antioxidantes e antiproliferativas em $P$. pyramidalis, sugerindo estudos farmacológicos. Os autores ainda enfatizaram que a flora das áreas semi-áridas brasileiras pode ser uma fonte valiosa de plantas ricas em taninos, compostos citotóxicos e agentes antioxidantes, importantes para tratamentos de câncer. Lima et al. (2006) observaram que as folhas e caules apresentam potenciais fontes de agentes antibióticos. Além disso, Guimarães et al. (2015) verificaram potencial controlador de Anagasta kuehniella, praga da traça da farinha do mediterrâneo e Santos et al. (2016) concluíram que o estrato de suas sementes são agentes promissores no controle biológico da cochonilha Dactylopius opuntiae, sendo uma tecnologia de baixo custo e ambientalmente correta.

Senegalia bahiensis (Benth) Seigler \& Ebinger é uma espécie endêmica do Brasil, encontrada nos estados de Al, BA, MG, PB, PE, PI, RJ, RN e SE, em Floresta Tropical e Restingas e recentemente no domínio Atlântico nos estados da BA, MG, PB, RJ e RN (Barros $\&$ Morim, 2014), sendo relatada em uso como alimento para bovinos e caprinos (Loiola et al., 2010). De acordo com Terra et al. (2014) e Terra \& Garcia (2014), S. bahiensis está sendo recomendada para inclusão na lista de espécies ameaçadas de extinção em Minas Gerais.

Enterolobium contortisiliquum (Vell.) Morong, popularmente conhecida como tamboril, orelhade-macaco, entre outros, é uma espécie nativa, não endêmica do Brasil, sendo sua madeira utilizada na fabricação de brinquedos, barcos e armações de móveis em geral (Lorenzi, 2008). No Brasil, ocorre nos domínios fitogeográficos da Caatinga, Cerrado e Mata Atlântica, com presença confirmada no Nordeste (BA, CE, PA, PB, PI, RN), no Centro-oeste (DF, GO, MS, MT), no Sudeste (MG, RJ, SP) e no Sul (PR, RS, SC) (Mesquita et al., 2018). Trannin et al. (2001) relatam tolerância da espécie a metais pesados, sendo promissora para pesquisas que objetivem a revegetação nessas áreas.
Foram realizados três experimentos: 1) minijardim multiclonal de Poicianella pyramidalis, conduzido entre outubro de 2012 a maio de 2013; 2) minijardim multiclonal de Senegalia bahiensis, conduzido entre dezembro de 2013 a junho de 2014; e 3) minijardim multiclonal de Enterolobium contortisiliquum, conduzido entre abril de 2014 a outubro de 2014. As temperaturas médias e umidade relativa do ar, no período de condução dos experimentos 1,2 e 3 foram $27,7^{\circ} \mathrm{C}$ e $67 \% ; 26,7^{\circ} \mathrm{Ce}$ $73,3 \%$; e $24,9{ }^{\circ} \mathrm{C}$ e de $76,7 \%$, respectivamente (Instituto Nacional de Meteorologia, 2017).

Os frutos de $P$. pyramidalis e $S$. bahiensis (Experimentos 1 e 2, respectivamente) foram coletados em matrizes localizadas em fragmentos da Caatinga em Castro Alves, BA, levados para o laboratório e após o período de cura, foram beneficiados, obtendo-se as sementes. As sementes de E. contortisiliquum, utilizadas no experimento 3 , foram obtidas de frutos coletados em matrizes localizadas no campus universitário de Cruz das Almas, BA, sendo levados para o laboratório e beneficiados após o processo de cura, para obtenção das sementes.

Após o beneficiamento das sementes, essas foram semeadas em tubetes de diferentes volumes (50, 180 e $280 \mathrm{~cm}^{3}$ ), preenchidos com substrato comercial Vivato Plus ${ }^{\circledR}$ e com adubação de base, utilizando adubo de liberação lenta, sendo que para o Experimento 1 foi usado o 14-14-14 (N-P-K) na dose de $1,5 \mathrm{Kg} \mathrm{m}^{-3}$ de substrato; para o Experimento 2, o 15-09-12 (N-P-K) na dose de 1,5 $\mathrm{Kg} \mathrm{m}^{-3}$ de substrato; e para o Experimento 3, o 14-14-14 (N-P-K) na dose de $2,24 \mathrm{~kg} \mathrm{~m}^{-3}$ de substrato.

Os tubetes foram acondicionados em bandejas de polietileno planas sem pé, com dimensões $60 \times 42 \mathrm{~cm}$, com capacidade de 192 tubetes de $50 \mathrm{~cm}^{3}$ e dimensões 63 x $48 \mathrm{~cm}$, com capacidade de 63 tubetes de 180 e 280 $\mathrm{cm}^{3}$, utilizando até $50 \%$ de sua capacidade.

As bandejas foram dispostas em bancadas de alumínio com um metro de altura, em casa de vegetação com sombrite $50 \%$ e plástico agrícola incolor.

Após o início da germinação, as mudas foram monitoradas com auxílio de uma régua graduada. Para a obtenção das minicepas, as mudas foram podadas, com auxílio de uma tesoura de poda, ao atingirem pelo menos $10 \mathrm{~cm}$ de altura, à altura de $8 \mathrm{~cm}$ da base, mantendo-se um par de folhas cortadas ao meio.

A obtenção das minicepas após o semeio ocorreu para o Experimento 1 aos 122 dias, para o Experimento 2 aos 80 dias e para o Experimento 3 aos 61 dias. 
Após a poda aérea (confecção das minicepas), essas receberam adubação de cobertura foliar e/ou via solo em intervalos de 7 dias. Para o minijardim multiclonal de P. pyramidalis foram realizadas duas adubações foliares e 8 adubações via solo. No minijardim multiclonal de S. bahiensis foram 15 foliares e 15 via solo. E para o minijardim multiclonal de E. contortisiliquum foram 10 foliares e 10 via solo.

Para obtenção da solução, diluiu-se $5 \mathrm{~mL}$ do produto West $\operatorname{gardem}{ }^{\circledR}$ foliar $\left(\mathrm{N}, \mathrm{K}_{2} \mathrm{O}_{5}, \mathrm{~K}_{2} \mathrm{O}, \mathrm{Co}, \mathrm{B}, \mathrm{Cu}, \mathrm{Mn}, \mathrm{Mo}, \mathrm{Zn}\right.$ e $\mathrm{Ni}$, contendo respectivamente, $129,6 \mathrm{gL}^{-1}, 21,66 \mathrm{gL}^{-1}, 10,8$ $\mathrm{gL}^{-1}, 0,054 \mathrm{gL}^{-1}, 0,108 \mathrm{gL}^{-1}, 0,54 \mathrm{gL}^{-1}, 0,54 \mathrm{gL}^{-1}, 0,054 \mathrm{gL}^{-1}$, $\left.1,08 \mathrm{gL}^{-1}, 0,054 \mathrm{gL}^{-1}\right)$ e raiz $\left(\mathrm{N}, \mathrm{K}_{2} \mathrm{O}_{5}, \mathrm{~K}_{2} \mathrm{O}, \mathrm{Co}, \mathrm{B}, \mathrm{Cu}, \mathrm{Mn}\right.$, $\mathrm{Mo}, \mathrm{Zn}$ e Ni, contendo respectivamente, $69.0 \mathrm{gL}^{-1}, 69,0 \mathrm{gL}^{-1}$, $69,0 \mathrm{gL}^{-1}, 0,0575 \mathrm{gL}^{-1}, 0,115 \mathrm{gL}^{-1}, 0.575 \mathrm{gL}^{-1}, 0,575 \mathrm{gL}^{-1}$, $\left.0,0575 \mathrm{gL}^{-1}, 1,150 \mathrm{gL}^{-1}, 0,0575 \mathrm{gL}^{-1}\right)$ em um litro de água. Aplicou-se $5 \mathrm{~mL}$ da solução por minicepa a cada 7 dias.

As brotações para confecção das miniestacas foram coletadas em intervalos de 15 dias para todos os experimentos. Porém, o início e o número de coletas realizadas diferiram em função da espécie trabalhada.

A quantificação das brotações de $P$. pyramidalis teve início a partir de 30 dias após a poda das mudas (poda da parte aérea, para confecção do minijardim), sendo realizadas 5 avaliações (aos 30, 45, 60, 75 e 90) e obtidas 3 safras de brotações (aos 60, 75 e 90 dias); a quantificação das brotações de $S$. bahiensis foi iniciada aos 18 dias após a poda das mudas $(18,33,48,63,78$, 93 e 109 dias) e foram coletadas 6 safras de brotos para confecção das miniestacas $(33,48,63,78,93$ e 109 dias após a poda). No experimento 3 (minijardim de E. contortisiliquum) a quantificação das brotações foi realizada após $30,45,60,75,90,105$ e 120 dias da poda das mudas, porém foram realizadas apenas 4 coletas de brotos para confecção das miniestacas $(60,75,105$ e 120 dias).

As coletas foram realizadas com auxílio de uma tesoura de poda, mantendo pelo menos uma gema axilar no local do corte, garantindo a possibilidade de emissão de novas brotações. As brotações coletadas apresentavam pelo menos $5 \mathrm{~cm}$ de comprimento, tamanho mínimo para a confecção das miniestacas.

As irrigações foram feitas manualmente, com regador, duas vezes ao dia para os três experimentos.

O delineamento experimental utilizado nos experimentos foi o inteiramente casualizado (DIC), com três volumes de tubetes $\left(50,180\right.$ e $\left.280 \mathrm{~cm}^{3}\right)$, constituindo três tratamentos com quatro repetições. Foram utilizadas
25 mudas por repetição, totalizando 100 minicepas por tratamento no Experimento 1; 20 mudas, totalizando 80 minicepas por tratamento para o Experimento 2; e 10 mudas, totalizando 40 minicepas por tratamento para o Experimento 3.

As variáveis analisadas foram: sobrevivência das minicepas, número de brotações por minicepa e número de miniestacas obtidas por minicepa, após sucessivas coletas.

Os resultados dos três experimentos foram submetidos à análise de variância (ANOVA) e comparados pelo teste de Tukey ao nível de 5\% de probabilidade. Para as variáveis que não atenderam aos pressupostos da ANOVA, utilizou-se a transformação $\sqrt{x+0,5}$. A sobrevivência em função do tempo foi avaliada segundo o método de parcela subdividida no tempo e regressão sequencial. Para realização das análises foi utilizado o software R Versão 3.1.3. (R Core Development Team, 2015).

\section{Resultados}

Verificou-se potencial de propagação vegetativa por miniestacas para as três espécies analisadas, uma vez que todas as minicepas de origem seminal cultivadas em tubetes emitiram brotações, com elevada sobrevivência após as sucessivas coletas de miniestacas.

Observou-se diferenças de sobrevivência em função do volume do tubete para as minicepas de Poincianella pyramidalis a partir de 75 dias após a instalação do minijardim, que corresponde à poda da parte aérea. As minicepas conduzidas em tubetes de $50 \mathrm{~cm}^{3}$ apresentaram maior mortalidade (20\%), enquanto que para as conduzidas naqueles com 180 e $280 \mathrm{~cm}^{3}$ a sobrevivência foi acima de $90 \%$ (Tabela 1). A sobrevivência das minicepas de P. pyramidalis, em tubetes de $50 \mathrm{~cm}^{3}$ e $280 \mathrm{~cm}^{3}$, reduziu em função do período de coleta, conforme equação linear simples (Figura 1). A mortalidade das minicepas conduzidas nos tubetes de $280 \mathrm{~cm}^{3}$ ficou abaixo de $9 \%$.

Não foi possível ajustar satisfatoriamente o modelo linear para as minicepas conduzidas nos tubetes de 180 $\mathrm{cm}^{3}$, pois os resíduos não apresentaram distribuição normal. Entretanto, observando os valores médios dentro de cada período, percebe-se que houve uma queda de sobrevivência de $100 \%$ para $92 \%$ entre as avaliações aos 30 e 45 dias após poda para a instalação do minijardim, ficando constante a partir da avaliação aos 45 dias (Tabela 1). 
Figura 1- Sobrevivência das minicepas de Poincianella pyramidalis, conduzidas em diferentes volumes de tubete após sucessivas coletas de miniestacas.

Figure 1. Survival of Poicianella pyramidalis ministumps, grown in different tube sizes, after successive collections.
Tubete de 50

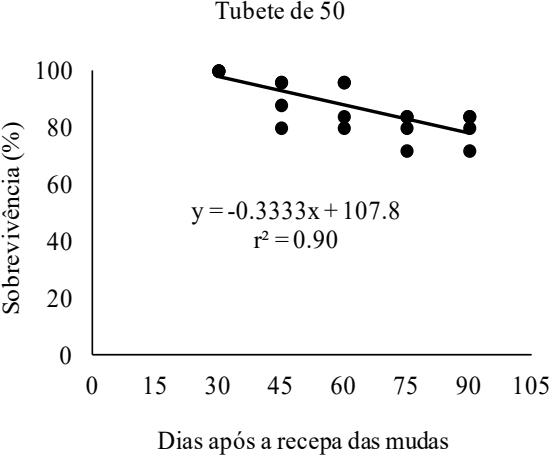

Tabela 1. Percentagem de sobrevivência de minicepas de Poincianella pyramidalis, conduzidas e manejadas em tubetes de diferentes volumes, após sucessivas coletas.

Table 1. Survival percentage of Poicianella pyramidalis ministumps, grown in different tube sizes, after successive collections

\begin{tabular}{cccc}
\hline \multirow{2}{*}{$\begin{array}{c}\text { Período } \\
\text { (dias)* }\end{array}$} & \multicolumn{3}{c}{ Volume do tubete } \\
\cline { 2 - 4 } & $\mathbf{5 0 \mathbf { c m } ^ { \mathbf { 3 } }}$ & $\mathbf{1 8 0} \mathbf{c m}^{\mathbf{3}}$ & $\mathbf{2 8 0 \mathbf { ~ m } ^ { \mathbf { 3 } }}$ \\
\hline 30 & $100 \mathrm{a}$ & $100 \mathrm{a}$ & $100 \mathrm{a}$ \\
45 & $90 \mathrm{a}$ & $92 \mathrm{a}$ & $93 \mathrm{a}$ \\
60 & $89 \mathrm{a}$ & $92 \mathrm{a}$ & $91 \mathrm{a}$ \\
75 & $80 \mathrm{~b}$ & $92 \mathrm{a}$ & $91 \mathrm{a}$ \\
90 & $80 \mathrm{~b}$ & $92 \mathrm{a}$ & $91 \mathrm{a}$ \\
\hline
\end{tabular}

Médias seguidas pela mesma letra nas linhas não diferem entre si pelo teste de Tukey a $5 \%$ de probabilidade $(\mathrm{CV} \%=3,9)$. Dias após a poda das mudas (implantação do minijardim multiclonal).

Observa-se dentro de cada período que as minicepas conduzidas em tubetes de maiores volumes $\left(180 \mathrm{~cm}^{3} \mathrm{e}\right.$ $280 \mathrm{~cm}^{3}$ ) permitiram maior produtividade de brotações por minicepa de Poincianella pyramidalis (Tabela 2), não se diferenciando da produtividade dos tubetes de 50 $\mathrm{cm}^{3}$ apenas nos períodos de 60 e 75 dias após a poda.

Dentro de cada recipiente, o período de maior produtividade de brotações ocorreu aos 60 dias após a poda das mudas (instalação do minijardim multiclonal), não apresentando diferença a partir de 45 dias para a produtividade das minicepas conduzidas em tubetes de $280 \mathrm{~cm}^{3}$ (Tabela 2).

Apesar da produção de brotações ter iniciado aos 30 dias nos minijardins de $P$. pyramidalis, apenas aos 60 dias após a poda observou-se brotações com tamanho mínimo para confecção das miniestacas com $5 \mathrm{~cm}$ de comprimento (Tabela 3), não havendo diferença de produtividade para o minijardim conduzido no tubete de maior volume nas três coletas realizadas. A condução das minicepas em tubetes de volume reduzido $\left(50 \mathrm{~cm}^{3}\right)$ afetou a produção total de miniestacas por minicepas, resultando em menor número de miniestacas em relação aos tubetes de $280 \mathrm{~cm}^{3}$, que apresentaram maior eficiência.

Tabela 2. Produtividade média de brotações por minicepa (PBM) após sucessivas coletas $(30,45,60,75$ e 90 dias após a poda) e média da produção total de brotações por minicepa (MBT) de Poincianella pyramidalis.

Table 2. Average productivity of ministumps sprouts (PBM) of Poincianella pyramidalis after successive collection (30,45, 60, 75 and 90 days after pruning) and average total sprouts production by ministumps (MBT).

\begin{tabular}{|c|c|c|c|c|c|c|c|}
\hline \multirow{2}{*}{ Tratamento } & \multicolumn{5}{|c|}{ PBM } & \multirow{2}{*}{ MBT } & \multirow{2}{*}{$\mathrm{CV}(\%)$} \\
\hline & 30 & 45 & 60 & 75 & 90 & & \\
\hline Т 50 & 1,47 b D & $2,15 \mathrm{~b} \mathrm{C}$ & 3,20 a A & 2,75 a B & $2,55 \mathrm{~b} \mathrm{~B}$ & $2,42 \mathrm{~b}$ & 6,19 \\
\hline Т 180 & 1,77 ab C & 2,92 a B & 3,72 a A & 3,22 a $B$ & $2,87 \mathrm{ab} \mathrm{B}$ & $2,92 \mathrm{a}$ & 7,63 \\
\hline Т 280 & 2,00 a B & 3,15 a A & 3,67 a A & 3,50 a A & 3,22 a A & $3,10 \mathrm{a}$ & 16,78 \\
\hline CV (\%) & 9,99 & 4,34 & 14,66 & 12,47 & 10,08 & & \\
\hline
\end{tabular}

Médias seguidas por mesma letra minúscula nas colunas e maiúscula nas linhas não diferem entre si pelo teste de Tukey a $5 \%$. T50, T180 e T280 = tubetes com $50 \mathrm{~cm}^{3}, 180 \mathrm{~cm}^{3}$ e $280 \mathrm{~cm}^{3}$, respectivamente; $\mathrm{CV}(\%)=$ coeficiente de variação. 
Tabela 3. Produção média de miniestacas por minicepa por período avaliado (PMM) e média da produção total de miniestacas por minicepa (MPT) de Poincianella pyramidalis.

Table 3. Average production of minicuttings by ministumps of Poincianella pyramidalis by evaluated period (PMM) and average of total production of minicuttings by ministump (MPT).

\begin{tabular}{|c|c|c|c|c|c|}
\hline \multirow{2}{*}{ Tratamento } & \multicolumn{3}{|c|}{ PMM } & \multirow{2}{*}{ MPT } & \multirow{2}{*}{$\mathrm{CV}(\%)$} \\
\hline & 60 & 75 & 90 & & \\
\hline T 50 & 0,44 a A & $0,21 \mathrm{~b} \mathrm{~B}$ & 0,19 b B & $0,28 \mathrm{~b}$ & 14,5 \\
\hline Т 180 & 0,47 a A & $\begin{array}{c}0,39 \mathrm{ab} \\
\mathrm{AB}\end{array}$ & $0,29 \mathrm{ab} B$ & $0,38 \mathrm{ab}$ & 23,4 \\
\hline Т 280 & 0,62 a A & 0,46 a A & 0,34 a A & $0,47 \mathrm{a}$ & 29,0 \\
\hline CV (\%) & 10,02 & 18,23 & 13,80 & & \\
\hline
\end{tabular}

Médias seguidas por mesma letra minúscula nas colunas e maiúscula nas linhas, dentro de uma mesma variável, não diferem entre si pelo teste de Tukey a 5\%, para PMM e MPT. T50, T180 e T280 =: tubetes com $50 \mathrm{~cm}^{3}$, $180 \mathrm{~cm}^{3}$ e $280 \mathrm{~cm}^{3}$, respectivamente; CV(\%) = coeficiente de variação. Em PMM, os dados foram transformados por $\sqrt{\chi+0,5}$.

\section{Experimento 2: Minijardim de Senegalia bahiensis}

Observou-se $100 \%$ de sobrevivência de minicepas de $S$. bahiensis a partir dos 18 dias após a poda e após seis coletas sucessivas de miniestacas, independente dos volumes dos tubetes usados.

A maior produtividade de brotações (PMB) de $S$. bahiensis ocorreu nas minicepas conduzidas em tubetes de $280 \mathrm{~cm}^{3}$ nos períodos de 33, 48 e 63 dias após a poda, não se diferenciando daquelas produzidas em tubetes de $180 \mathrm{~cm}^{3}$ nos períodos de 18, 78, 93 e 109 (Tabela
4). Ao final do período avaliado, a produção total das brotações das minicepas (MBT) conduzidas em tubetes de maiores volumes não se diferenciou estatisticamente, apresentando 2,9 e 3,1 brotações por minicepas em tubetes de $180 \mathrm{~cm}^{3}$ e $280 \mathrm{~cm}^{3}$, respectivamente.

Dentro de cada recipiente, a maior produtividade de brotações ocorreu no último período de avaliação, aos 109 dias após a implantação do minijardim, para os tubetes de $55 \mathrm{~cm}^{3}$ e $180 \mathrm{~cm}^{3}$, e no segundo período de avaliação (33 dias após a poda) para as minicepas conduzidas no tubete de $280 \mathrm{~cm}^{3}$, que em seguida caiu, se recuperando apenas no último período de coleta. A maior produção total de brotações (MBT) foi obtida pelas minicepas conduzidas nos recipientes de maiores volumes (Tabela 4).

A coleta de miniestacas iniciou aos 33 dias após a poda, sendo obtida maior produção de miniestacas nos recipientes de maiores volumes (Tabela 5).

Com relação à produção total de miniestacas por minicepas (Tabela 5), observou-se que tubetes de $50 \mathrm{~cm}^{3}$ resultaram em menor número de miniestacas e o maior número foi obtido nas minicepas conduzidas em tubete de maior volume $\left(280 \mathrm{~cm}^{3}\right)$.

Notou-se, também, que as minicepas de $S$. bahiensis conduzidas nos tubetes de $280 \mathrm{~cm}^{3}$ obtiveram maior produção aos 33 dias após a poda, com 1,8 miniestacas por minicepas. Nas coletas referentes aos períodos 48 e 63 dias após a poda, percebeu-se que a produtividade caiu bruscamente para os minijardins conduzidos no tubetes de maiores volumes.

Tabela 4. Produtividade média de brotações por minicepa (PBM) após sucessivas coletas (18, 33, 48, 63, 78, 93 e 109 dias após a poda) e média da produção total de brotações por minicepa (MBT) de Senegalia bahiensis.

Table 4. Average productivity of ministumps sprouts (PBM) of Senegalia bahiensis after successive collections (18, 33, 48, 63, 78, 93 and 109 days after pruning) and average total sprouts production by ministumps (MBT).

\begin{tabular}{|c|c|c|c|c|c|c|c|c|c|}
\hline \multirow{2}{*}{ Tratamento } & \multicolumn{7}{|c|}{ PBM } & \multirow{2}{*}{ MBT } & \multirow{2}{*}{ CV(\%) } \\
\hline & 18 & 33 & 48 & 63 & 78 & 93 & 109 & & \\
\hline Т 50 & $3,2 \mathrm{bBC}$ & $3,1 \mathrm{cBC}$ & $2,8 \mathrm{cC}$ & $3,0 \mathrm{cBC}$ & $3,8 \mathrm{bB}$ & $3,9 \mathrm{bB}$ & $5,1 \mathrm{bA}$ & $2,4 b$ & 6,2 \\
\hline Т 180 & $5,0 \mathrm{a} B$ & $4,9 \mathrm{bBC}$ & $4,1 \mathrm{bD}$ & $4,2 \mathrm{bCD}$ & $5,4 \mathrm{aAB}$ & $5,0 \mathrm{aAB}$ & $5,9 \mathrm{aA}$ & $2,9 a$ & 7,6 \\
\hline Т 280 & $5,3 \mathrm{aBC}$ & $6,4 \mathrm{aA}$ & $4,7 \mathrm{aC}$ & $4,9 \mathrm{aC}$ & $5,3 \mathrm{aBC}$ & $5,1 \mathrm{aBC}$ & $5,9 \mathrm{aAB}$ & $3,1 \mathrm{a}$ & 16,8 \\
\hline $\mathrm{CV}(\%)$ & 8,0 & 8,2 & 7,9 & 8,0 & 9,3 & 6,7 & 7,4 & & \\
\hline
\end{tabular}

Médias seguidas por mesma letra minúscula nas colunas e maiúscula nas linhas não diferem entre si pelo teste de Tukey a 5\%. T50, T180 e T280=: tubetes com $50 \mathrm{~cm}^{3}, 180 \mathrm{~cm}^{3}$ e $280 \mathrm{~cm}^{3}$, respectivamente; $\mathrm{CV}(\%)=$ coeficiente de variação. 
Tabela 5. Produção média de miniestacas por minicepas de Senegalia bahiensis por período avaliado (PMM) e média da produção total de miniestacas por minicepa (MPT) .

Table 5. Average production of minicuttings by ministumps of Senegalia bahiensis by evaluated period (PMM) and average of total production of minicuttings by ministump (MPT).

\begin{tabular}{|c|c|c|c|c|c|c|c|}
\hline \multirow{2}{*}{ Tratamento } & \multicolumn{6}{|c|}{ PMM } & \multirow{2}{*}{ MPT } \\
\hline & 33 & 48 & 63 & 78 & 93 & 109 & \\
\hline T 50 & $0,25 \mathrm{cA}$ & $0,24 \mathrm{aA}$ & $0,19 \mathrm{bA}$ & $0,10 \mathrm{bA}$ & $0,16 \mathrm{bA}$ & $0,12 \mathrm{cA}$ & $0,18 \mathrm{c}$ \\
\hline Т 180 & $0,84 \mathrm{bA}$ & $0,35 \mathrm{aBC}$ & $0,16 \mathrm{bC}$ & $0,37 \mathrm{abBC}$ & $0,40 \mathrm{bBC}$ & $0,56 \mathrm{bAB}$ & $0,45 \mathrm{~b}$ \\
\hline Т 280 & $1,80 \mathrm{aA}$ & 0,35 a C & 0,41 a $\mathrm{C}$ & $0,79 \mathrm{aB}$ & $0,87 \mathrm{aB}$ & $0,87 \mathrm{aB}$ & $0,87 \mathrm{a}$ \\
\hline $\mathrm{CV}(\%)$ & 10,78 & 17,94 & 29,68 & 30,86 & 17,07 & 12,80 & \\
\hline
\end{tabular}

Médias seguidas por mesma letra minúscula nas colunas e maiúscula nas linhas não diferem entre si pelo teste de Tukey a 5\%. T50, T180 e T280 =: tubetes com $50 \mathrm{~cm}^{3}, 180 \mathrm{~cm}^{3}$ e $280 \mathrm{~cm}^{3}$, respectivamente; $\mathrm{CV}(\%)=$ coeficiente de variação. Em PMM, os dados foram transformados $\sqrt{\chi+0,5}$.

\section{Experimento 3: Minijardim de Enterolobium contortisiliquum}

A produtividade média de brotações de $E$. contortisiliquum, apresentou diferença estatística apenas aos 75 dias, após a instalação do minijardim multiclonal, em que a maior produtividade foi para as minicepas conduzidas nos tubetes de $280 \mathrm{~cm}^{3}$, porém, não se diferenciando das minicepas conduzidas no tubete de $180 \mathrm{~cm}^{3}$. Dentro de cada recipiente os períodos de maior produtividade foram aos 60 e 75 dias, após instalação do minijardim, porém não se diferenciando dos períodos seguintes (Tabela 6).

Apesar do volume de tubete utilizado para a condução dos minijardins de $E$. contortisiliquum não terem afetado o número de brotações por minicepas (MBT) ao final do período de condução do experimento (Tabela 6), afetou a produtividade média final das miniestacas por minicepas (MPT), como pode ser observado na Tabela 7.
Mesmo com o início da produção de brotos 30 dias após a poda (Tabela 6), não foi possível a confecção de miniestacas em todos os períodos avaliados (Tabela 7).

De forma geral, a primeira produção de miniestacas de E. contortisiliquum ocorreu 60 dias após a poda e em seguida aos 75 dias. Apenas após 30 dias (105 dias da poda) foi possível uma nova coleta para confecção das miniestacas, seguida por mais uma coleta aos 120 dias.

Um fato que merece destaque no minijardim de E. contortisiliquum, foi que além da produção de miniestacas ter ocorrido apenas a partir da terceira quantificação das brotações (60 dias após a poda das mudas) foi possível observar que a produção ocorreu de forma cíclica, ou seja, a cada 30 dias não havia produção e quando retornavam a produzir, na avaliação seguinte, as minicepas apresentavam baixa produtividade indicando, que coletas sucessivas em intervalos curtos pode não favorecer a produtividade das minicepas dessa espécie.

Tabela 6. Produtividade média de brotações por minicepas (PBM) após sucessivas coletas (30, 45, 60, 75, 90, 105 e 120 dias após a poda) e média da produção total de brotações (MBT) por minicepas de Enterolobium contortisiliquum.

Table 6. Average productivity of ministumps sprouts (PBM) after successive collections (30, 45, 60, 75, 90, 105 and 120 days after pruning) and average total sprouts production by ministumps (MBT) of Enterolobium contortisiliquum.

\begin{tabular}{|c|c|c|c|c|c|c|c|c|c|}
\hline \multirow{2}{*}{ Tratamento } & \multicolumn{7}{|c|}{ PBM } & \multirow{2}{*}{ MBT } & \multirow{2}{*}{ CV $(\%)$} \\
\hline & 30 & 45 & 60 & 75 & 90 & 105 & 120 & & \\
\hline Т 50 & $3,5 \mathrm{aA}$ & $3,3 \mathrm{aA}$ & $3,5 \mathrm{aA}$ & $3,4 \mathrm{bA}$ & $3,4 \mathrm{aA}$ & $3,8 \mathrm{aA}$ & $3,6 \mathrm{aA}$ & $3,51 \mathrm{a}$ & 27,6 \\
\hline Т 180 & $3,6 \mathrm{aA}$ & $3,3 \mathrm{aA}$ & $3,8 \mathrm{aA}$ & $3,7 \mathrm{abA}$ & $3,5 \mathrm{aA}$ & $3,6 \mathrm{aA}$ & $3,7 \mathrm{aA}$ & $3,62 \mathrm{a}$ & 17,6 \\
\hline Т 280 & $3,5 \mathrm{aB}$ & $3,6 \mathrm{aB}$ & $4,2 \mathrm{aA}$ & 4,2 aA & $3,9 \mathrm{aAB}$ & $3,9 \mathrm{aAB}$ & $3,8 \mathrm{aAB}$ & $3,89 \mathrm{a}$ & 18,6 \\
\hline CV (\%) & 10,26 & 11,33 & 10,03 & 9,13 & 7,72 & 8,42 & 4,53 & & \\
\hline
\end{tabular}

Médias seguidas por mesma letra minúscula nas colunas e maiúscula nas linhas não diferem entre si pelo teste de Tukey a 5\%. T50, T180 e T280 = tubetes com $50 \mathrm{~cm}^{3}, 180 \mathrm{~cm}^{3}$ e $280 \mathrm{~cm}^{3}$, respectivamente; $\mathrm{CV}(\%)=$ coeficiente de variação. 
Tabela 7. Produção média de miniestacas por minicepas de Enterolobium contortisiliquum por período avaliado (PMM) e média da produção total de miniestacas por minicepa (MPT).

Table 7. Average production of minicuttings by ministumps of Enterolobium contortisiliquum by evaluated period (PMM) and average of total production of minicuttings by ministump (MPT).

\begin{tabular}{ccccccr}
\hline & \multicolumn{5}{c}{ PMM } & \\
\cline { 2 - 5 } Tratamento & 60 & 75 & 105 & 120 & & MPT \\
\hline T 50 & $0,27 \mathrm{aA}$ & $0,35 \mathrm{aA}$ & $0,25 \mathrm{abAB}$ & $0,10 \mathrm{bB}$ & & $0,20 \mathrm{~b}$ \\
T 180 & $0,32 \mathrm{aB}$ & $0,67 \mathrm{aA}$ & $0,20 \mathrm{bB}$ & $0,82 \mathrm{aA}$ & & $0,51 \mathrm{a}$ \\
T 280 & $0,35 \mathrm{aB}$ & $0,72 \mathrm{aAB}$ & $0,37 \mathrm{aB}$ & $1,07 \mathrm{aA}$ & $0,63 \mathrm{a}$ \\
\hline CV (\%) & 14,69 & 19,34 & 16,84 & 16,60 & \\
\hline
\end{tabular}

Médias seguidas por mesma letra minúscula nas colunas e maiúscula nas linhas não diferem entre si pelo teste de Tukey a 5\%. T50, T180 e T280 = tubetes com $50 \mathrm{~cm}^{3}, 180 \mathrm{~cm}^{3} \mathrm{e} 280 \mathrm{~cm}^{3}$, respectivamente; $\mathrm{CV}(\%)=$ coeficiente de variação. Dados de PMM foram transformados $\sqrt{\chi+0,5}$.

\section{Discussão}

De acordo com Souza Junior et al. (2008), que avaliaram o potencial de minijardim de Grevillea robusta conduzido em tubetes, em minijardins bem manejados espera-se que as minicepas atinjam sobrevivência superior a $90 \%$. Neste sentido, infere-se que para $P$. pyramidalis tubetes de $50 \mathrm{~cm}^{3}$ não são adequados para utilização em minijardim, devendo optar pelos recipientes de 180 e $280 \mathrm{~cm}^{3}$, já que a sobrevivência das minicepas se manteve acima de $90 \%$, após sucessivas coletas (Tabela 1).

Souza et al. (2009) relatam elevada capacidade de produção de miniestacas em minicepas de Toona ciliata conduzidas em tubetes de $280 \mathrm{~cm}^{3}$, variando de 1,1 a 5,1 estacas em intervalos de dois meses entre coletas. No presente trabalho, a produtividade se mostrou menor, porém o intervalo entre coletas foi de apenas 15 dias.

Nota-se que ao longo das coletas a maior produção de miniestacas por minicepa de Poincianella pyramidalis foi aos 60 dias, primeira coleta, para os três volumes de tubetes, em seguida houve queda na produtividade do minijardim (Tabela 3). Isso pode estar ligado ao vigor fisiológico das minicepas e da nutrição não apropriada para a espécie, sugerindo a necessidade de futuros trabalhos voltados para determinação da nutrição e intervalos de coleta apropriados, que de acordo com Cunha et al. (2005), o uso de intervalos maiores para coleta de miniestacas pode favorecer a produtividade do minijardim, uma vez que as minicepas sofrerão menos estresse. Além disso, Souza et al. (2009) concluíram que quanto maior o intervalo entre coletas, maior a velocidade de crescimento das mudas originadas pelas miniestacas.

Elevada taxa de sobrevivência (100\%) das minicepas de E. contortisiliquum foi verificada após sucessivas coletas, independente do volume do recipiente utilizado para condução dos minijardins. Justino et al. (2017), Mantovani et al. (2017), Oliveira et al. (2015) e Souza Junior et al. (2008) também observaram 100\% de sobrevivência das minicepas de Myracrodruon urundeuva Allemão, Peltophorum dubium Spreg. Taub, Handroanthus heptaphyllus Mattos e Grevillea robusta A. Cunn., respectivamente, após sucessivas coletas, semelhante ao observado para Senegalia bahiensis nesse trabalho.

De acordo com Fernandes et al. (2017), altos percentuais de sobrevivência de minicepas mostra a tolerância das espécies a podas periódicas, indicando grande potencial da técnica da miniestaquia.

De acordo com Wendling et al. (2005), o maior volume dos recipientes para condução das minicepas, levará à maior produção de raízes pelas minicepas e, consequentemente, levará à maior produção de brotos, podendo o intervalo entre coletas sucessivas ser maior.

Ferreira et al. (2012) observaram que a produção de miniestacas por minicepas por coleta variou de 1,4 a $2,5 \mathrm{em}$ tubetes de $205 \mathrm{~cm}^{3}$. Já no presente trabalho essa produção variou de 0,10 a 1,80 em função do volume de tubete, em que as minicepas de Enterolobium contortisiliquum conduzidas em tubetes de maiores volumes apresentaram maiores produções (Tabela 5). A maior produção de miniestacas nos tubetes maiores pode estar relacionada ao melhor desenvolvimento do sistema radicular em decorrência do maior volume de substrato (Wendling et al., 2005). Além disso, Silva et al. (2012) comentam que o uso de tubetes para condução de minicepas requer maior frequência de irrigação e reposição de nutrientes em função de seu reduzido volume. Portanto, entende-se que quanto menor o volume de substrato, maior será o risco de restrição nutricional, o que pode causar redução na produção de miniestacas.

O curto intervalo entre coleta de miniestacas (15 dias) utilizado neste estudo pode não ter sido favorável, o que contribuiu para a queda na produtividade de $S$. bahiensis ao decorrer das sucessivas coletas. Autores como Brondani et al. (2012), Peña et al. (2015) e Wendling 
et al. (2007) também observaram tendência de exaustão nas coletas sucessivas de brotações, culminando com a diminuição da produtividade. Cunha et al. (2005) comentam que em função da espécie trabalhada, a adoção de intervalos longos entre uma coleta e outra de miniestacas pode ser favorável, pois as minicepas sofrerão menos estresse, aumentando a produtividade, o que pode levar a uma produção mais regular.

Coletas sucessivas promovem a remoção de nutrientes do substrato, como foi constatado pelo trabalho realizado por Souza et al. (2014) sobre a produtividade de minicepas de cedro australiano. Portanto, a remoção de nutrientes do substrato pode ter sido um dos fatores que resultaram na oscilação da produção de miniestacas de E. contortisiliquum.

A queda brusca de produtividade observada para minicepas de $S$. bahiensis pode ter sido, segundo Titon et al. (2003), em função da exaustão nutricional das minicepas, causado pelo curto intervalo de coleta das miniestacas, sugerindo que este intervalo deverá ser aumentado para a manutenção da sua produtividade. Após este período nota-se uma ligeira recuperação na produtividade das minicepas (a partir de 78 dias) conduzidos nos tubetes de maiores volumes, no entanto, não se igualando à produção inicial. Para reduzir a exaustão das minicepas, Cunha et al. (2005) recomendam que o intervalo entre uma coleta e outra seja de 25 a 30 dias, pois isso reduzirá o número de intervenções nas minicepas, diminuindo assim o estresse sofrido.

No trabalho de Souza Junior et al. (2008) com Grevillea robusta A. Cunn., também foi observada oscilação na produtividade das minicepas, havendo um período de maior produtividade seguido por outro de baixa produção, voltando a aumentar no período seguinte. Para Xavier et al. (2013), esta oscilação é devido às condições de vigor fisiológico das minicepas e também em relação à manutenção do minijardim clonal. Assim, para cada espécie é necessário determinar o intervalo entre coletas, bem como os períodos de adubação mais adequados, visando o manejo eficiente do minijardim e, de acordo com Hartmann et al. (2011), o manejo e a nutrição são fatores que influenciam o bom desempenho dos minijardins.

\section{Conclusões}

Houve alta sobrevivência das minicepas de Poincianella pyramidalis, Senegalia bahiensis e
Enterolobium contortisiliquum, após sucessivas coletas de miniestacas, indicando potencial da técnica de miniestaquia.

O uso de tubetes de volume reduzido pode afetar de forma negativa a produtividade de brotações e, consequentemente, o número de miniestacas por minicepa.

\section{Agradecimentos}

Ao Conselho Nacional de Desenvolvimento Científico e Tecnológico (CNPq) pela concessão de bolsa do Programa Institucional de Bolsas de Iniciação Científica (Pibic) a autora Sandra Selma Marques de Souza.

\section{Referências}

Abreu, A. H. M. de et al. Produção de mudas e crescimento inicial em campo de Enterolobium contortisiliquum produzidas em diferentes recipientes. Floresta, v. 45, n. 1, p. 141-150, 2015. DOI: 10.5380/ rf.v45i1.28931.

Antunes, C. G. C. et al. Desenvolvimento de mudas de catingueira em diferentes substratos e níveis de luminosidade. Cerne, v. 20, n. 1, p. 55-60. 2014. DOI: 10.1590/S0104-77602014000100007.

Araújo, A. P. \& Paiva Sobrinho, S. Germinação e produção de mudas de tamboril (Enterolobium contortisiliquum (Vell.) Morong) em diferentes substratos. Revista Árvore, v. 35, n. 3, nesp, p. 581-588, 2011. DOI: 10.1590/S0100-67622011000400001.

Barbosa, M. D. et al. Florística e fitossociologia de espécies arbóreas e arbustivas em uma área de Caatinga em Arcoverde, PE, Brasil.

Revista Árvore, v. 36, n. 5, 2012, p. 851-858. DOI: 10.1590/S010067622012000500007.

Barretto, S. S. B. \& Ferreira, R. A. Aspectos morfológicos de frutos, sementes, plântulas e mudas de leguminosae e mimosoidae: Anadenanthera columbria (Vellozo) Brenan e Enterolobium contortisiliquum (Vellozo) Morong. Revista Brasileira de Sementes, v. 33, n. 2, p. 223-232, 2011. DOI: 10.1590/S010131222011000200004.

Barros, M. J. F. \& Morim, M. P. Senegalia (Leguminosae, Mimosoideae) from the Atlantic Domain, Brazil. Systematic Botany, v. 39, n. 2, p. 452-477, 2014. DOI: 10.1600/036364413X680807.

Brondani, G. E. et al. Miniestaquia de Eucalyptus benthamii $x$ Eucalyptus dunnii: (I) Sobrevivência de minicepas e produção de miniestacas em função das coletas e estações do ano. Ciência Florestal, v. 22, n. 1, p. 11-21, 2012. DOI: 10.5902/198050985075.

Coêlho, I. A. M. et al. Efeito de recipientes e tipo de substratos na qualidade das mudas de Poincianella pyramidalis (Tul.) L. P. Queiroz. Scientia Plena, v. 9, n. 5, 2013.

Costa, G. M. da et al. Variações locais na riqueza florística em duas ecorregiões de caatinga. Rodriguésia, v. 66, n. 3, p. 685-709, 2015. DOI: $10.1590 / 2175-7860201566303$. 
Cunha, A. C. M. C. M. da et al. Miniestaquia em sistema de hidroponia e em tubetes de corticeira-do-mato. Ciência Florestal, v. 18 , n. 1, p. 85-92, 2008. DOI: 10.5902/19805098513.

Cunha, A. C. M. C. M. da et al. Produtividade e sobrevivência de minicepas de Eucalyptus benthamii Maiden et Cambage em sistema de hidroponia e em tubete. Ciência Florestal, v. 15, n. 3, p. 307-310, 2005. DOI: $10.5902 / 198050981868$.

Dantas, B. F. et al. Produção de mudas de catingueira-verdadeira (Caesalpinia pyramidalis Tul.) em função de substratos e luminosidades. Científica, v. 39, n. 1/2, p. 34-43, 2011. DOI: $10.15361 / 1984-5529.2011 v 39 n 1 \% 2 F 2 p 34+-+43$.

Dantas, B. F. et al. Taxas de crescimento de mudas de catingueira submetidas a diferentes substratos e sombreamentos. Revista Árvore, v. 33, n. 3, p. 413-423, 2009. DOI: 10.1590/S010067622009000300003 .

Dias, P. C. et al. Estaquia e miniestaquia de espécies florestais lenhosas do Brasil. Pesquisa Florestal Brasileira, v. 32, n. 72, p. 453-462, 2012. DOI: 10.4336/2012.pfb.32.72.453.

Diógenes, A. G. et al. Avaliação da produção de miniestacas em minicepas de Myracrodruon urundeuva Fr. All. (Aroreira). Revista Científica Eletrônica de Engenharia Florestal, v. 21, n. 1, p. 49-57, 2013.

Fabaceae. In: Flora do Brasil 2020 em construção. Rio de Janeiro: Jardim Botânico do Rio de Janeiro, [2018]. Disponível em: $<$ http:// floradobrasil.jbrj.gov.br/reflora/floradobrasil/FB109818>. Acesso em: 05 Set. 2018.

Fernandes, S. P. et al. Altura de decepa para estabelecimento de minijardim clonal de nim (Azadirachta indica A. Juss). Revista Agropecuária Científica no Semiárido, v. 13, n. 1, p. 67-71, 2017.

Ferreira, D. de A. et al. Influência da posição das miniestacas na qualidade de mudas de cedro australiano e no seu desempenho inicial no pós-plantio. Ciência Florestal, v. 22, n. 4, p. 715-723, 2012. DOI: $10.5902 / 198050987553$.

Ferreira, E. M. et al. Determinação do tempo ótimo do enraizamento de miniestacas de clones de Eucalyptus spp. Revista Árvore, v. 28, p. 183-187, 2004. DOI: 10.1590/S0100-67622004000200004.

Ferreira, E. V. R. et al. Floristic list from a Caatinga remnant in Poço Verde, Sergipe, Brazil. Check List: Journal of species lists and distribution, v. 9, n. 6, p. 1354-1360, 2013. DOI: 10.15560/9.6.1354.

Ferriani, A. P. et al. Produção de brotações e enraizamento de miniestacas de Piptocarpha angustifolia. Pesquisa Florestal Brasileira, v. 31, n. 67, p. 257-264, 2011. DOI: 10.4336/2011. pfb.31.67.257.

Freitas, T. A. S. de et al. Enraizamento de miniestacas de Enterolobium contortisiliquum em garrafas PET. Revista Agrogeoambiental, v. 9, n. 3, 2017. DOI: 10.18406/2316-1817v9n32017968.

Gonçalves, F. G. et al. Emergência e qualidade de mudas de Enterolobium contortisiliquum (Vell.) Morong (Fabaceae) em diferentes substratos. Revista Árvore, v. 37, n. 6, p. 1125-1133, 2013. DOI: $10.1590 / \mathrm{S} 0100-67622013000600014$.
Guimarães, L. C. et al. Purification and characterization of a Kunitz inhibitor from Poincianella pyramidalis with insecticide activity against the Mediterranean flour moth. Pesticide Biochemistry and Physiology, v. 118, p.1-9, 2015. DOI: 10.1016/j.pestbp.2014.12.001.

Hartmann, H. T. et al. Plant propagation: principles and practices. 8th ed. São Paulo: Prentice-Hall, 2011. 915 p.

Instituto Nacional de Meteorologia. Disponível em: <http://www. inmet.gov.br/portal/>. Acesso em: 2 maio 2017.

Justino, S. T. P. et al. Sistema de manejo em minijardim clonal de Myracrodruon urundeuva Allemão. Agropecuária Científica no Semiárido, v. 13, n. 3, p. 255-263, 2017. DOI: 10.30969/acsa. v13i3.910.

Leite, A. V. \& Machado, I. C. Biologia reprodutiva da "catingueira" (Caesalpinia pyramidalis Tul., Leguminosae-Caesalpinioideae), uma espécie endêmica da Caatinga. Revista Brasileira de Botânica, v. 32, n. 1, p. 79-88, 2009. DOI: 10.1590/S0100-84042009000100008.

Lima, A. L. da S. et al. Crescimento de Hymenaea courbaril L. var. stilbocarpa (Hayne) Lee et Lang. e Enterolobium contortisiliquum (Vell.) Morong (Leguminosae) sob diferentes níveis de sombreamento. Acta Amazônica, v. 40, n. 1, p. 43 - 48, 2010. DOI: 10.1590/S004459672010000100006.

Lima, C. R. de et al. Qualidade fisiológica de sementes de diferentes árvores matrizes de Poincianella pyramidalis (Tul.) L. P. Queiroz. Revista Ciência Agronômica, v. 45, n. 2, p. 370-378, 2014. DOI: 10.1590/S1806-66902014000200019.

Lima, M. R. F. de et al. Anti-bacterial activity of some Brazilian medicinal plants. Journal of Ethnopharmacology, v. 105, p. 137-147, 2006. DOI: 10.1016/j.jep.2005.10.026.

Lima, T. M.; et al. Influence of temperature and photoperiod on the germination of Senegalia bahiensis Seeds. Semina: Ciências Agrárias, v. 38 , n. 3 , p. $1103-1114$, 2017. DOI: $10.5433 / 1679-0359.2017$ v38 n3p1103.

Loiola, M. I. B. et al. Leguminosas e seu potencial de uso em comunidades rurais de São Miguel do Gostoso - RN. Revista Caatinga, v. 23, n. 3, p. 59-70, 2010.

Lorenzi, H. Árvores brasileiras: manual de identificação e cultivo de plantas arbóreas do Brasil. 5 ed. Nova Odessa, SP: Instituto Plantarum, 2008. v. 1. 384 p.

Maia, G. N. Caatinga: árvores e arbustos e suas utilidades. São Paulo: D\&Z, 2004. 413 p.

Mantovani, N. et al. Cultivo de canafístula (Peltophorum dubium) em minijardim clonal e propagação por miniestacas. Ciência Florestal, v. 27, n. 1, p. 225-236, 2017. DOI: 10.5902/1980509826461.

Melo, J. G. de et al. Antiproliferative activity, antioxidant capacity and tannin content in plants of Semi-Arid Northeastern Brazil. Molecules, v. 15 , p. $8534-8542$, 2010. DOI: 10.3390/molecules 15128534.

Melo, R. R. et al. Crescimento inicial de mudas de Enterolobium contortisiliquum (Vell.) Morong. sob diferentes níveis de luminosidade. Revista Brasileira de Ciências Agrárias, v. 3, n. 2, p. 138-144, 2008. DOI: 10.5039/agraria.v3i2a263. 
Mendonça, A. V. R.; et al. Morfologia de frutos e sementes e germinação de Poincianella pyramidalis (Tul.) L. P. Queiroz, comb. Nov. Ciência Florestal, v. 26, n. 2, p. 375-387, 2016. DOI: $10.5902 / 1980509822738$.

Mendonça, A. V. R. et al. Produção e armazenamento de sementes de Poincianella pyramidalis (Tul.) L. P. Queiroz, em resposta a diferentes ambientes de coleta. Revista Brasileira de Ciências Agrárias, v. 9, n. 3, p. 413-419, 2014. DOI: 10.5039/agraria. v9i3a2589.

Mesquita, A. L. et al. Enterolobium in: Flora do Brasil 2020 em construção. Jardim Botânico do Rio de Janeiro, [2018]. Disponível em: <http://floradobrasil.jbrj.gov.br/reflora/floradobrasil/FB83154>. Acesso em: 05 Set. 2018

Oliveira, T. P. F. de et al. Productivity of polyclonal minigarden and rooting of Handroanthus heptaphyllus Mattos minicuttings. Semina: Ciências Agrárias, v. 36, n. 4, p. 2423-2432, 2015. DOI: $10.5433 / 1679-0359.2015 \mathrm{v} 36 \mathrm{n} 4 \mathrm{p} 2423$.

Peña, M. L. P. et al. Época de coleta e ácido indolbutírico no enraizamento de miniestacas de pitangueira. Semina: Ciências Agrárias, v. 36, n. 5, p. 3055-3068, 2015. DOI: $10.5433 / 1679-0359.2015 v 36 n 5 p 3055$

Pimenta, A. C. et al. Miniestaquia e anatomia caulinar de pinhãomanso em quatro épocas de coleta. Comunicata Scientiae, v. 5, n. 4, p. 478-485, 2014.

R Core Development Team. R: R Version 3.1.3 (2015-03-09). Viena: The R Foundation for Statistical Computing, 2015.

Santos, A. C. da S. et al. Controlling Dactylopius opuntiae with Fusarium incarnatum - equiseti species complex and extracts of Ricinus communis and Poincianella pyramidalis. Journal of Pest Science, v. 89, n. 2, p. 539-547, 2016. DOI: 10.1007/s10340-0150689-4.

Scalon, S. de P. Q. et al. Germinação e crescimento inicial da muda de orelha-de-macaco (Enterolobium contortisiliqunn (Vell.) Morong): efeito de tratamentos químicos e luminosidade. Revista Árvore, v. 30, n. 4, p. 529-536, 2006. DOI: 10.1590/S010067622006000400005 .

Silva, A. D. P. da et al. Tratamentos para superação de dormência em sementes de Enterolobium contortisiliquum (Vell.) Morong. Revista Verde, v. 9, n. 2, p. 213-217, 2014.

Silva, M. P. S. da et al. Enraizamento de miniestacas e produtividade de minicepas de cedro australiano manejadas em canaletões e tubetes. Ciência Florestal, v. 22, n. 4, p. 703-713, 2012. DOI: $10.5902 / 198050987552$.
Silva, R. L. da et al. Propagação clonal de guanandi (Calophyllum brasiliense) por miniestaquia. Revista Agronomía Costarricense, v. 34, n. 1, p. 99-104, 2010.

Souza, J. C. A. V. de et al. Propagação vegetativa de cedro-australiano (Toona ciliata M. Roemer) por miniestaquia. Revista Árvore, v. 33, n. 2, p. 205-213, 2009. DOI: 10.1590/S0100-67622009000200002.

Souza Junior, L. de et al. Miniestaquia de Grevillea robusta A. Cunn. a partir de propágulos juvenis. Ciência Florestal, v. 18, n. 4, p. 455-460, 2008. DOI: 10.5902/198050987552.

Souza, J. S. de et al. Produtividade de minicepas de cedro australiano e remoção de nutrientes pela coleta sucessiva de miniestacas. Ciência Florestal, v. 24, n. 1, p. 71-77, 2014. DOI: 10.5902/1980509813324.

Terra, V. et al. Patterns of geographic distribution and conservation of Acacieae Benth. (Leguminosae-Mimosoideae), in Minas Gerais, Brazil. Brazilian Journal of Botany, v. 37, n. 2, p. 151-158, 2014. DOI: $10.1007 / \mathrm{s} 40415-014-0052-7$.

Terra, V. \& Garcia, F. C. P. Acacieae Benth. (Leguminosae, Mimosoideae) in Minas Gerais, Brazil. Brazilian Journal of Botany, v. 37, n.4, p. 609-630, 2014. DOI: 10.1007/s40415-0140100-3.

Titon, M. et al. Eficiência das minicepas e microcepas na produção de propágulos de clones de Eucalyptus grandis. Revista Árvore, v. 27, n. 5, p. 619-625, 2003. DOI: 10.1590/S0100-67622003000500004.

Trannin, I. C. B. et al. Crescimento e nodulação de Acacia mangium, Enterolobium contortisiliquum e Sesbania virgata em solo contaminado com metais pesados. Revista Brasileira de Ciência do Solo, v. 25, n. 3, p.743-753, 2001.

Xavier, A. et al. Silvicultura clonal: princípios e técnicas. 2 ed. Viçosa, MG: UFV, 2013. 280 p.

Wendling, I. et al. Indução de brotações epicórmicas ortotrópicas para a propagação vegetativa de árvores adultas de Araucaria angustifólia. Revista Agronomia Costarricense, v. 33, n. 2, p. 309-319, 2009.

Wendling, I. et al. Produção de mudas de corticeira-do-mato por miniestaquia a partir de propágulos juvenis. Colombo: Embrapa Florestas, 2005. 5 p. (Embrapa Florestas. Comunicado técnico, 130).

Wendling, I. et al. Produção e sobrevivência de miniestacas e minicepas de erva-mate cultivadas em sistema semi-hidropônico. Pesquisa Agropecuária Brasileira, v. 42, n. 2, p. 289-292, 2007. DOI: 10.1590/S0100-204X2007000200019. 